\title{
Exploratory Research of New Curve Number System
}

\author{
Wen Jia Tan ${ }^{1}$, Jen Feng Khor ${ }^{1}$, Lloyd Ling ${ }^{1}$ and Yuk Feng Huang ${ }^{1 *}$ \\ ${ }^{1}$ Lee Kong Chian Faculty of Engineering and Science, Universiti Tunku Abdul Rahman, 41600 \\ Kajang Selangor, Malaysia
}

\begin{abstract}
In the past, the $C N$ was determined through SCS handbook. In order to determine runoff prediction using SCS-CN model, selection of $C N$ is important. However, the conventional $C N$ methodology with inappropriate $C N$ selection often produces inconsistent runoff estimation. Thus, the new direct curve number derivation technique based on rainfallrunoff datasets with supervised numerical optimization technique under the guide of inferential statistics was developed to improve the accuracy of surface runoff prediction. Furthermore, the two decimal point $C N$ system was proposed in this study. The optimum $C N$ of Melana site is 90.45 at alpha 0.01 with $\mathrm{BCa} 99 \%$ confidence interval range from 90.45 to 95.12 . The regional specific calibrated SCS-CN model with two decimal point $C N$ derivation technique is out-performed the runoff prediction of conventional SCS-CN model and the asymptotic curve number fitting method.
\end{abstract}

\section{Introduction}

Recent year, due to rapid urbanization, the flooding scenarios occur more frequently in main city of Malaysia thus the rainfall-runoff model plays an important role in planning and managing the water resource system and flood control. There are various types of rainfallrunoff models available. Since 1954, the Soil Conservation Service Curve Number (SCS$\mathrm{CN}$ ) is one of the most popular rainfall-runoff model to predict direct runoff amount from agricultural site and then extended to urban watershed due to its simplicity. Nowadays, the SCS-CN model is incorporated into various software such as ArcGIS [15, 54, 55], remote sensing $[15,29,35]$ and SWAT $[24,41]$. The SCS-CN method also adopted by Malaysian government agencies and used as teaching purpose in engineering hydrology textbook.

Unfortunately, the accuracy and consistency of surface runoff prediction by using the curve number method derived from SCS had been questioned by some hydrologist from various countries $[1,8-9,13,16-18,25,27,30,33,37-39,50,53,56]$. There was a study proved that by using tabulated $C N$ values had a tendency to over-predict runoff amount [37]. Furthermore, a study in South Korea concluded that by referring the tabulated $C N$ unable obtained satisfied runoff estimation [24]. The tabulated $C N$ groups the effect of land use and land cover condition, hydrologic soil group (HSG), and antecedent runoff condition (ARC) based on watershed characteristics into a single coefficient [3, 42-45, 51]. As a

\footnotetext{
* Corresponding author: huangyf@utar.edu.my
} 
result, $C N$ is the most important parameter in SCS-CN model. Wrong selection of $C N$ will lead to inappropriate runoff prediction [17]. In 1954, the SCS-CN model was used $C N$ handbook to search the suitable $C N$ value to represent the watershed. The $C N$ value was then substituted into the $C N$ formula as shown in Eq. 1 to find the maximum potential water retention of watershed $(S)$. By fixing $\lambda=0.2$ with $S$ value and event rainfall $(P)$ substituted into the base SCS-CN model as shown in Eq. 2, the surface runoff $(Q)$ could be determined.

$$
\begin{gathered}
C N=\frac{25,400}{S+254} \\
Q=\frac{\left(P-I_{a}\right)^{2}}{P-I_{a}+S} ; I_{a}=\lambda S ; P>I_{a}, Q \neq 0 ; P<I_{a}, Q=0
\end{gathered}
$$

Where,

$C N=$ Curve Number Value

Error! Reference source not found. = Runoff depth $(\mathrm{mm})$

$P \quad=$ Rainfall depth (mm)

$I_{a} \quad=$ the initial abstraction $(\mathrm{mm})$

$S \quad=$ maximum potential water retention of a watershed $(\mathrm{mm})$

Basically, the $C N$ is dimensionless watershed index which ranged from 0 to 100 to represent a watershed from high infiltration to fully permeable respectively. All the tabulate $C N$ and charts of $C N$ available in the Soil Conservation Service (SCS) National Engineering Handbook Section 4: Hydrology (NEH-4) [42-45] for agricultural areas, as well as Technical Release 55 (TR-55) [51] and applied in Technical Release 20 (TR-20) software for small and big urban catchments respectively were derived based on approximately 199 experimental watersheds in United States of America (USA) that ranged in size from 0.0971 ha to 18,600 ha which were located at 23 locations nationwide, using measurements of annual maximum rainfall and runoff collected between 1928 and 1954 and thousands of infiltrometer tests [49]. However, the information about the initial development of the curve number method has not been preserved [19, 50, 51].

The NRCS handbook [42-45] was created based on the hydrological condition and the soil group type in United States of America (USA) thus the soil condition and hydrological situation in Malaysia might not be the same as USA. There is a possibility to obtain unsuitable soil group type for a particulate watershed in Malaysia and thus produces unrealistic runoff volume. As a result, the SCS-CN practitioners should not blindly adopted the $C N$ values in NRCS handbook [42-45], TR-55 [51] and TR-20 software. Although the SCS-CN model had integrated with remote sensing (RS) and geological information sensing (GIS) to produce a high resolution remote sensing imagery, the number of land cover types described in NEH-4 [42-45], TR-55 [51] and applied in TR-20 software was still so enormous that it was hard to classify into appropriate $C N$ categories accurately [6]. As a result, Hawkins (1998) and Canters et al. (2006) [4, 20] suggested that $C N$ tables should only be used as a guideline, and the actual $C N$ should be determined based on local and regional data. Many researchers developed the $C N$ calculation methods by incorporating the land cover information and the original $C N$ in TR-55 [14] but the $C N$ still unable to represent the regional specific watershed. In order to improve the surface runoff prediction result, most of the SCS practitioners practiced a common approach by "trial and error" to tweak the $C N$ based on observed data without any statistical justification. By using "trial and error" method cannot obtain a consistent $C N$ to represent particular watershed. 


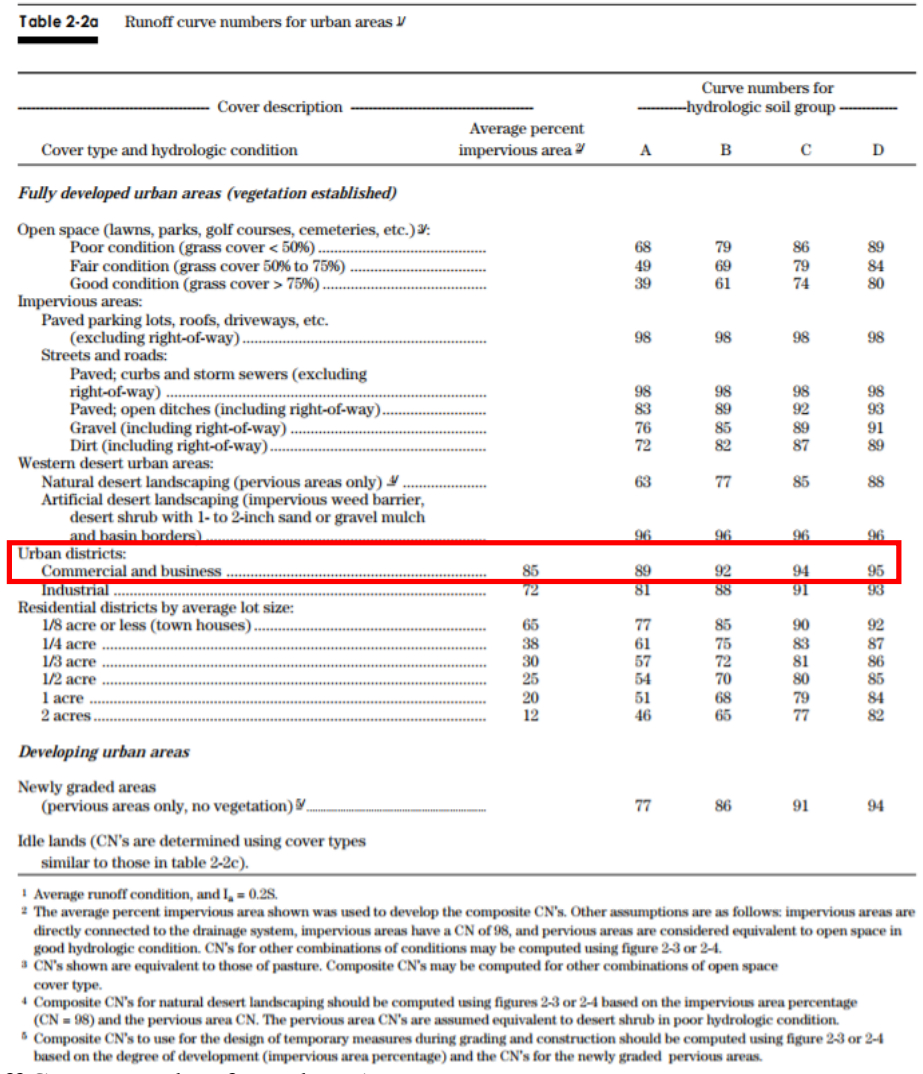

Fig. 1. Runoff Curve Number for Urban Area

Source: Table 2.2a. USDA, 1986, pp 2-5 [51])

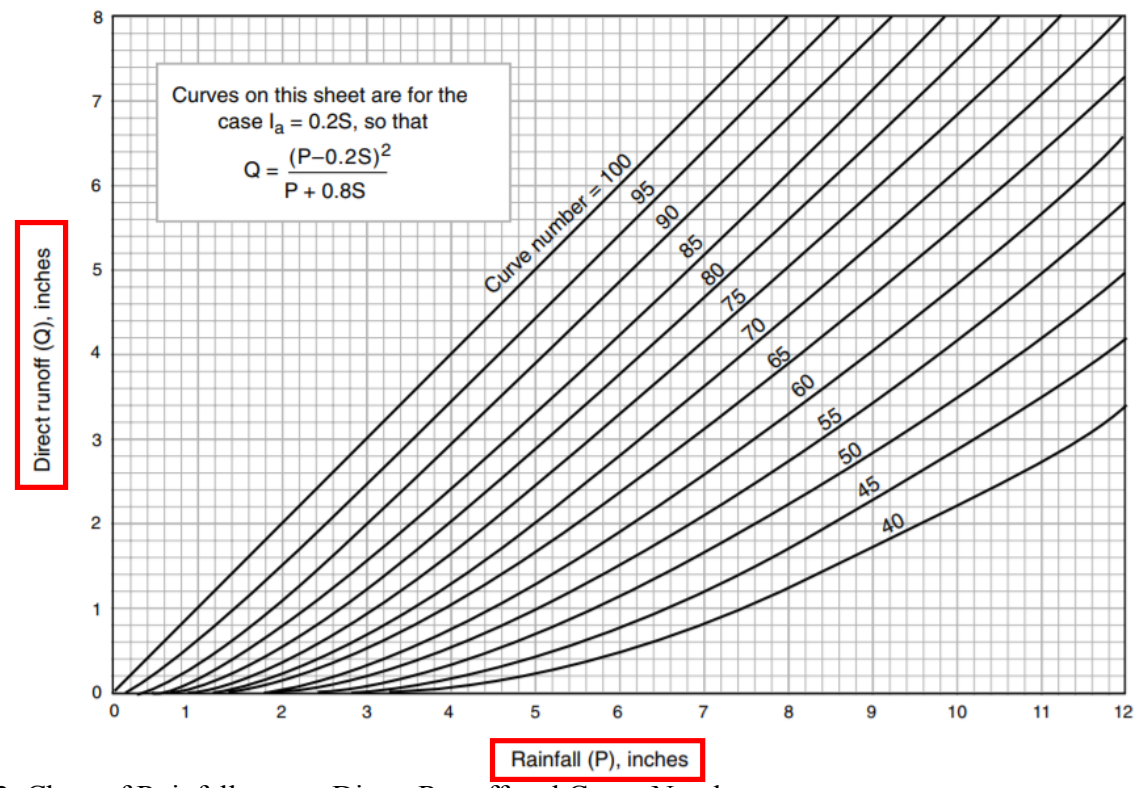

Fig. 2. Chart of Rainfall versus Direct Runoff and Curve Number.

Source: Figure 2.1. USDA, 1986, pp 2-2 [51]) 
Recent decades, most of the research studies used the recorded daily rainfall-runoff $(P$ $Q)$ data pairs from local or nearby watershed to derive the local $C N$ value $[17,21,22,46-$ 47]. There was few approaches for $C N$ determination from observed $P-Q$ data had been reported such as least-squares method (LSM) [50] and asymptotic fitting method (AFM) $[17,19]$. The asymptotic fitting method created by Professor Hawkins was based on frequency matching concept. The rainfall-runoff data were sorted separately in descending order. The asymptotic fitting method basically classified into three different response behavior which was standard behavior, complacent behavior and violent behavior. For complacent behavior, there was no constant $C N$ can be obtained. The asymptotic fitting method had been applied in some earlier research studies [2, 8, 34, 40, 49] In 2014, there was a study in Sicily by D'Asaro et al (2012) [8] discovered that the $C N$ values found by the asymptotic fitting and least-squares fitting methods were all lower than the tabulated $C N$ in handbook table [8]. In summary, there are two issues to be addressed in this article as stated below:

Issue 1: Limitation of NRCS handbook in choosing an exact curve number.

Issue 2: The regional specific curve number should be rounded or not.

As a result, in this study will present a new approach to derive regional specific $C N$ based on direct $P-Q$ data sets under the guide of non-parametric inferential statistics and a new $C N$ system with at least two decimal point is proposed to solve all issues above.

\section{Data and methodology}

\subsection{Study site}

In this study, Melana watershed is chosen to demonstrate the regional specific urban SCS model and new $C N$ system. Melana watershed is located at Johor, Malaysia between $1^{\circ} 30^{\prime} \mathrm{N}$ to $1^{\circ} 35^{\prime} \mathrm{N}$ and $103^{\circ} 35^{\prime} \mathrm{E}$ to $103^{\circ} 39^{\prime} \mathrm{E}$ as shown in Fig 3 [5]. The total area of whole Melana watershed is $21.12 \mathrm{~km}^{2}$. There are total of twenty-seven data sets of rainfall-runoff event between July 2004 to October 2004 were adopted from Chan (2005) [5] as shown in Table 1 [5]. Due to rapid urbanization in Melana watershed, there was only $20 \%$ of Melana watershed was urbanized and after seven years later, more than $60 \%$ of the area would be residential area [32]. As a result, in order to prevent the rainfall-runoff data sets affected by land cover land use change in Melana watershed due to rapid development, there was only a short period of rainfall-runoff data pairs were used in this study.

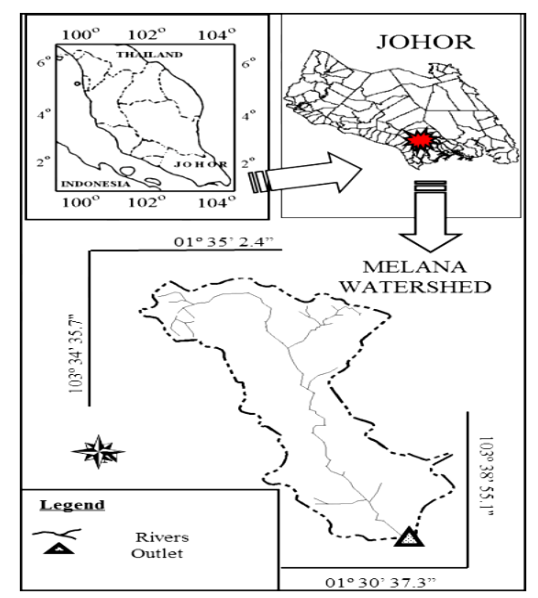

Fig. 3. Location of Melana Watershed (Source: Chan (2005) [5]) 
Table 1. Daily Rainfall-Runoff Event Data of Melana Watershed selected from July to October 2004. (Source: Chan (2005) [5])

\begin{tabular}{|c|c|c|c|c|c|}
\hline No. & $\begin{array}{l}\text { Daily Rainfall } \\
\text { (mm) }\end{array}$ & $\begin{array}{c}\text { Daily Runoff } \\
(\mathrm{mm})\end{array}$ & No. & $\begin{array}{l}\text { Daily Rainfall } \\
\text { (mm) }\end{array}$ & $\begin{array}{c}\text { Daily Runoff } \\
\text { (mm) }\end{array}$ \\
\hline 1 & 0.054 & 0.020 & 15 & 7.918 & 1.300 \\
\hline 2 & 0.192 & 0.022 & 16 & 8.505 & 1.194 \\
\hline 3 & 0.480 & 0.029 & 17 & 16.976 & 3.055 \\
\hline 4 & 1.337 & 0.042 & 18 & 19.328 & 3.284 \\
\hline 5 & 1.501 & 0.314 & 19 & 22.246 & 4.253 \\
\hline 6 & 2.041 & 0.112 & 20 & 29.371 & 9.062 \\
\hline 7 & 2.067 & 0.098 & 21 & 33.404 & 6.131 \\
\hline 8 & 2.129 & 0.133 & 22 & 33.417 & 7.844 \\
\hline 9 & 2.634 & 0.198 & 23 & 34.665 & 6.875 \\
\hline 10 & 3.825 & 0.490 & 24 & 36.272 & 6.922 \\
\hline 11 & 3.939 & 0.372 & 25 & 40.804 & 11.320 \\
\hline 12 & 4.183 & 0.420 & 26 & 52.373 & 13.127 \\
\hline 13 & 4.926 & 0.270 & 27 & 61.643 & 36.212 \\
\hline 14 & 6.948 & 0.891 & & & \\
\hline
\end{tabular}

\subsection{Methodology}

In this study, the non-parametric inferential statistics Bootstrapping technique, Bias corrected and accelerated (BCa) procedure with 2,000 sampling [11-12] was conducted by the help of supervised numerical optimisation technique to calibrate the base SCS-CN model and derived the regional specific $C N$ for Melana watershed through the $P-Q$ datasets directly. The Bootstrapping $\mathrm{BCa}$ statistics was chosen due to its robustness nature and the inferential ability via its confidence interval $[7,10,52]$. At the same study site, the Null hypothesis had been set up and all had been rejected in the previous research study in 2015 and 2017 by Ling [26-28] and also concluded the lambda value should not equal to 0.2 . Furthermore, the $99 \%$ confident interval (CI) range for $\lambda$ and $S$ were found out in previous publication too. In this research results having the same conclusion as previous research study [26-28], the lambda value fixed at 0.2 being rejected due to 0.2 was not in the $\lambda$ confident interval range of $(0.0004,0.0005)$. The regional specific equivalent $C N_{0.2}$ value for Melana site could be derived by using $C N$ formula $(C N=25,400 /(S+254))$ which was proposed by SCS for $C N$ comparison $[19,23]$. The $S_{\lambda}$ needed to correlate using general $S_{\lambda}$ formula derived by Ling (2017) [27] as shown in Eq. 3 to substitute back into the $C N$ formula.

$$
S_{\lambda}=\frac{\left[P-\frac{(\lambda-1) Q}{2 \lambda}\right]-\sqrt{P Q-P^{2}+\left[P-\frac{(\lambda-1) Q}{2 \lambda}\right]^{2}}}{\lambda}
$$

Throughout this study, the derived $C N$ value and new $C N$ system will be created for Melana watershed. 


\subsection{Runoff Model Assessment}

There are three types runoff model assessment with formulas as stated below:

$$
\begin{gathered}
E=1-\frac{R S S}{\sum_{i=1}^{n}\left(Q_{\text {predicted }}-Q_{\text {mean }}\right)^{2}} \\
R S S=\sum_{i=1}^{n}\left(Q_{\text {predicted }}-Q_{\text {observed }}\right)^{2} \\
B I A S=\frac{\sum_{i=1}^{n}\left(Q_{\text {predicted }}-Q_{\text {observed }}\right)}{n}
\end{gathered}
$$

$Q=$ Runoff amount $(\mathrm{mm})$

$n=\quad$ Total number of datasets

$E=$ Nash-Sutcliffe index

$R S S=$ Residual sum of squares

The three runoff model assessment as shown in Eq. 4, Eq. 5 and Eq. 6 are used to assess the asymptotic curve number model, calibrated SCS-CN model and conventional SCS-CN model. The lower the RSS value, the better the predictive model. Zero value of $B I A S$ indicates the predictive model has zero error. For positive BIAS value means the predictive model has tendency to over-predict and vice versa. $E$ between 0.0 to 1.0 indicates it is a perfect predictive model. When $E<0$, the predictive model performs worse than using the mean value to predict the dataset [31]. 


\section{Result and discussion}

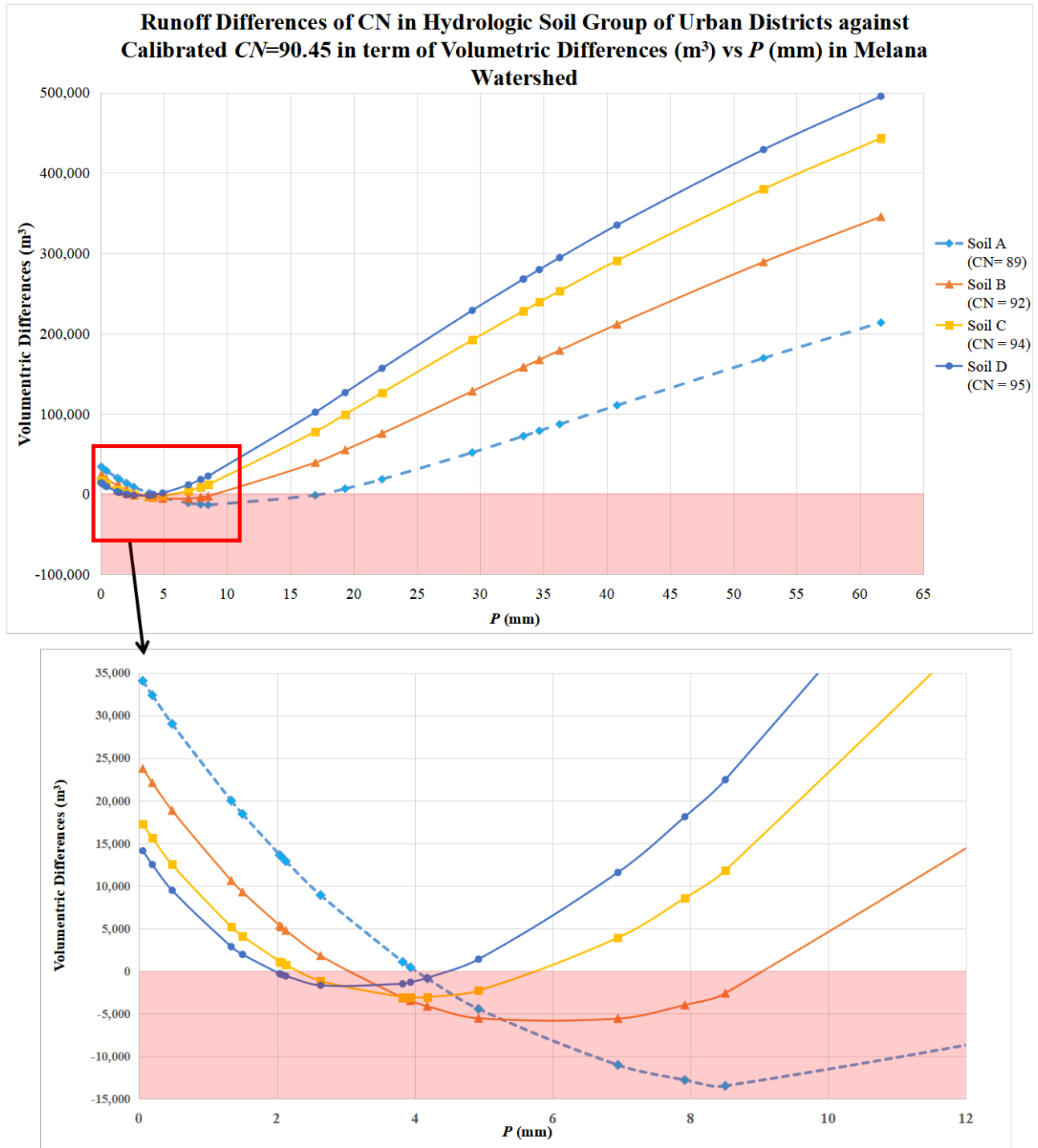

Fig. 4. Graph of Runoff Differences of $C N$ in Hydrologic Soil Group of Urban Districts against Calibrated $C N$ in term of Volumetric Difference vs Precipitation.

There are two issues had been proposed to solve as stated in introduction. First of all, the $C N$ chosen from tabulated handbook is not sensitive due to a big gap in between $C N$ range. The exact $C N$ cannot pick correctly by referring to the NEH-4 handbook [42-45]. However, the accurate regional specific $C N$ for Melana watershed can be calculated by using Eq. (1) under the guide of inferential statistic to exact decimal. The calculated $C N$ of Melana watershed is 90.45 with significant level at alpha 0.01 . The $C N$ 's $99 \%$ BCa confident interval of Melana watershed is $(90.45,95.12)$. According to NEH-4 handbook [42-45], the $C N$ of urban district with hydrological soil group $\mathrm{A}$ is 89 which is out of the obtained confident interval range of Melana watershed. Therefore, only soil group B, C and D are statistically significant to be considered for Melana watershed. Due to the climate change scenario and rapid urbanization posts a challenge to identify a suitable $C N$ for the Melana 
watershed via tabulated handbook. Therefore, by using NRCS handbook [42-45] to select $C N$ has a risk of committing Type II error. Based on the graph in Figure 4, it clearly shows that there is uncertainty in runoff volume when the precipitation is changing. When the precipitation is less than $12 \mathrm{~mm}$, the $C N$ selected from handbook under urban district for Melana site has the tendency to over-predict runoff amount up to 35 thousands $\mathrm{m}^{3}$ and under-predict up to 15 thousands $\mathrm{m}^{3}$. When the rainfall amount is more than $12 \mathrm{~mm}$, all the runoff volume for $C N=84,92,94$, and 95 will over-predict runoff amount up to 500 thousands $\mathrm{m}^{3}$. Moreover, Fig. 4 clearly shown that when the $C N$ increases from 85 to 95 , the runoff over prediction risk is significant and further magnified toward higher rainfall depth. As a result, by using NRCS handbook [42-45] having inconsistent runoff prediction.

There are some limitations of NEH-4 handbook [42-45]. Often in the tabulated $C N$ handbook, there will be sudden jumps in $C N$ choice based on four different hydrologic soil groups as shown in Fig 1. Moreover, by referring to the chart in handbook as stated in Fig 2 , the selection of $C N$ is in inches instead of SI unit and with a condition that $\lambda$ value in SCS-CN model must fixed at 0.2. $C N$ was proposed as whole number and still in use until today. However, rounding up the $C N$ will cause a huge differences in runoff volume even it is just different by one $C N$ class. This proves that $C N$ variation affects the direct runoff estimation more than rainfall variability. Figure 5 shows the graph of runoff volumetric difference when the calculated $C N=90.45$ has been round up to 91 and round down to 90 . It is obviously showed that the $C N$ should not be round up or round down to whole number $C N$. When $C N=91$, the runoff volume tends to over-predicted up to 300 thousand $\mathrm{m}^{3}$. The maximum over-predicted runoff volume is 255 thousands $\mathrm{m}^{3}$ when the $C N$ is 90 . Rounding the $C N$ causes a large amount of uncertainty runoff volumetric difference in Melana watershed.

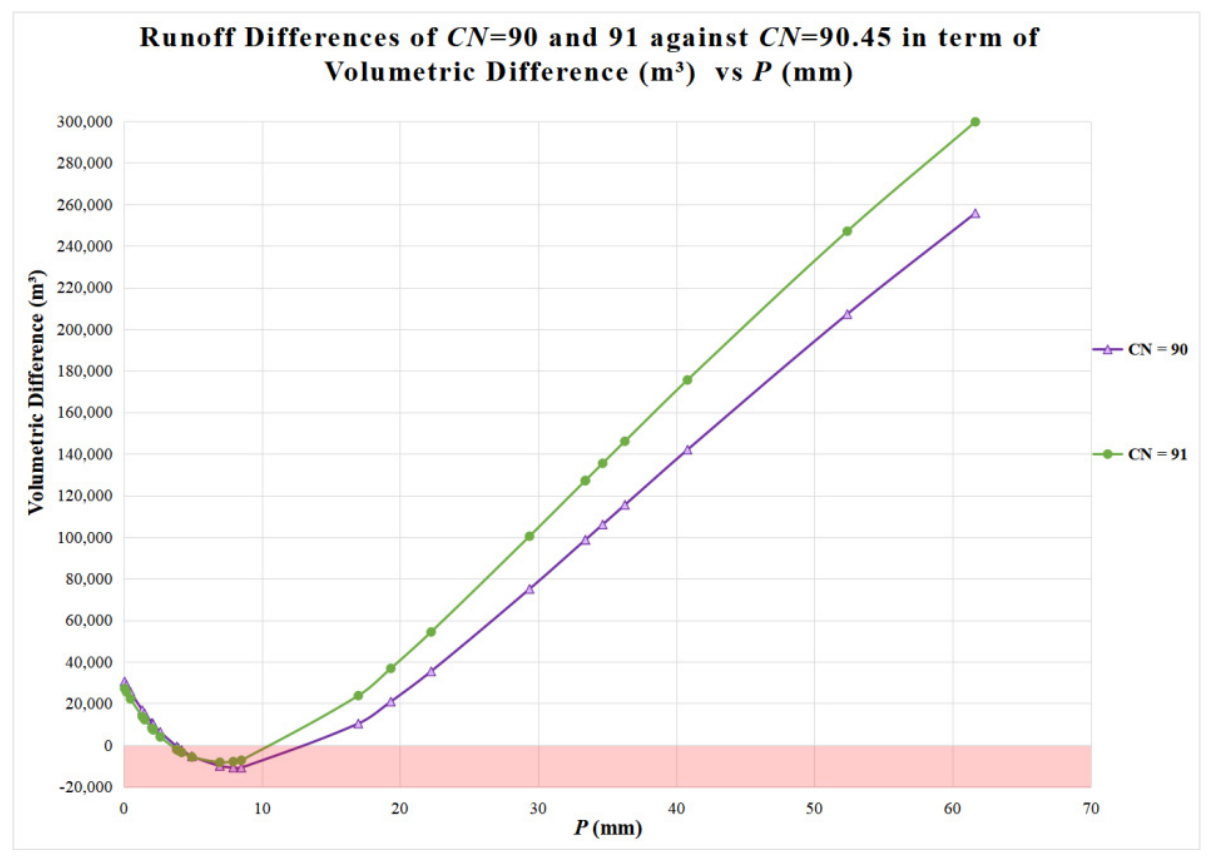

Fig. 5. Graph of Runoff Differences of $C N$ is 90 and 91 against Calibrated $C N$ in term of Volumetric Difference vs Precipitation. 


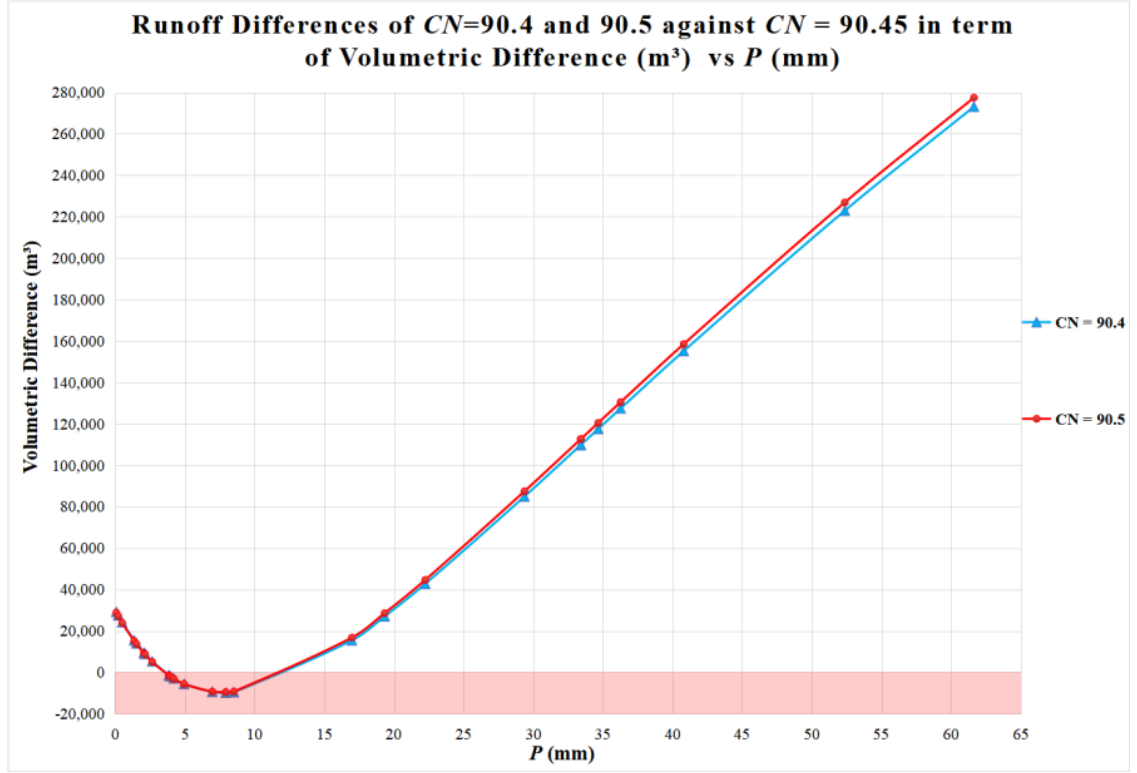

Fig. 7. Graph of Runoff Differences of one decimal point $C N$ against Calibrated $C N$ in term of Volumetric Difference vs Precipitation.

In this study, the new $C N$ system approach with at least two decimal point being proposed instead of one decimal point. This is because there is still over-predicted nearly 273 thousand $\mathrm{m}^{3}$ volumetric difference at rainfall depth of $61.6 \mathrm{~mm}$ under $C N=90.40$ as shown in Fig. 7 whereas the volumetric difference for two decimal point $C N=90.44$ is only 270 thousand $\mathrm{m}^{3}$ as shown in Fig. 8. When the rainfall amount increase, the runoff volume differences also increase. The volumetric difference for two decimal point $C N$ is smaller than one decimal point $C N$. Thus, the $C N$ should be proposed as at least two decimal point.

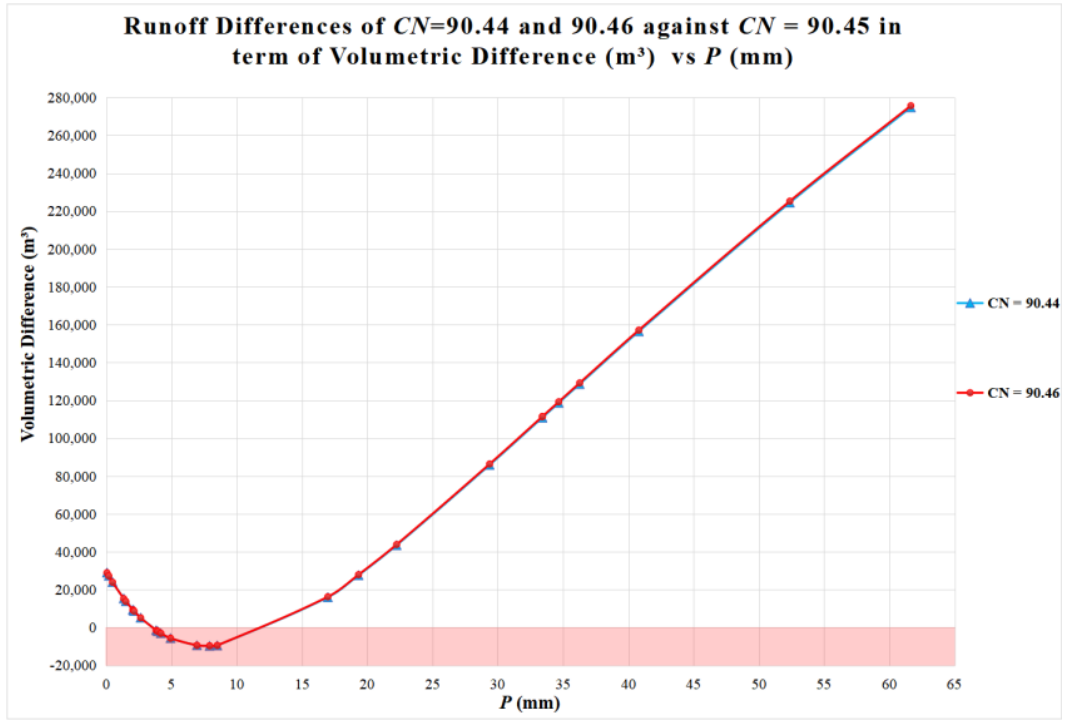

Fig. 8. Graph of Runoff Differences of two decimal point $C N$ against Calibrated $C N$ in term of Volumetric Difference vs Precipitation. 
Nowadays, most of the research studies used asymptotic $C N$ fitting method (AFM) to find $C N_{\infty}$ in order to avoid inconsistent runoff prediction based on tabulated $C N$ handbook. The $C N_{\infty}$ of Melana site is derived as 81.72 based on a previous research study in 2017 [26]. The accuracy of asymptotic $C N$ runoff model is benchmark to conventional SCS-CN model and calibrated SCS-CN model by using few predictive model as tabulated in Table 2. Based on Table 2, it obviously stated that the calibrated model has higher Nash-Sucliffe, lower RSS and BIAS almost near to zero. Furthermore, the $C N_{\infty}$ value determined by AFM model did not has statistical significant proof at alpha 0.01 .

Table 2. Assessment of Different Runoff Predictive Model.

\begin{tabular}{|l|c|c|c|}
\hline \multicolumn{1}{|c|}{ Predictive Model } & AFM Model & $\begin{array}{c}\text { Calibrated } \\
\text { Model }\end{array}$ & $\begin{array}{c}\text { Conventional } \\
\text { SCS Model }\end{array}$ \\
\hline $\boldsymbol{p}$ value & Not Significant & 0.01 & Not Significant \\
\hline $\boldsymbol{E}$ & 0.817 & 0.863 & -0.359 \\
\hline $\boldsymbol{R S S}$ & 264.703 & 198.150 & 1970.120 \\
\hline $\boldsymbol{B I} \boldsymbol{A S}$ & -0.172 & 0.187 & 4.927 \\
\hline $\boldsymbol{C} \boldsymbol{N}_{\mathbf{0 . 2}}$ & 81.72 & 90.45 & 94.47 \\
\hline $\begin{array}{l}\text { BCa 99\% Confident Interval Range } \\
\text { of } \boldsymbol{C N}_{\mathbf{0 . 2}}\end{array}$ & None & {$[90.45,95.12]$} & None \\
\hline Residual: Median & 0.618 & -0.052 & 0.473 \\
\hline (Skewness) Residual & -2.399 & -1.731 & 1.287 \\
\hline Kurtosis) Residual & 8.395 & 9.521 & 0.761 \\
\hline $\begin{array}{l}\text { BCa 99\% Confident Interval Range } \\
\text { of Median Residual }\end{array}$ & {$[-1.043,1.659]$} & {$[-0.231,-0.008]$} & {$[-0.065,7.831]$} \\
\hline Standard Deviation of Model error & 3.186 & 2.754 & 7.111 \\
\hline Variance (Residual) & 10.151 & 7.584 & 50.561 \\
\hline
\end{tabular}

Fig.9 shows the graph of three runoff predictive model against the observe runoff amount versus precipitation in Melana watershed. By using the calibrated SCS model, the obtained $I_{a}=0.043 \mathrm{~mm}$. The minimum observed rainfall amount is $0.054 \mathrm{~mm}$. This showed that the precipitate is more than initial abstraction, thus there is runoff generate. In the other hand, by applying the conventional SCS-CN model, the calculated $I_{a}$ is $2.971 \mathrm{~mm}$. According to SCS, any rainfall amount less than $I_{a}$ then no runoff generate. However, 1/3 of the rainfall events already violated the SCS constraint. Based on Fig.9 below, when the precipitation is less than $0.5 \mathrm{~mm}$, the runoff amount cannot be more than $0.5 \mathrm{~mm}$ rainfall depth while the predicted runoff depth from conventional SCS-CN and AFM model are higher than $0.5 \mathrm{~mm}$ rainfall depth. There is a huge different between the predicted runoff against the observed runoff depth when the precipitation reaches $61.6 \mathrm{~mm}$. The SCS-CN model tends to over-predicted up to 326 thousand $\mathrm{m}^{3}$ runoff (equivalent to 130 Olympic size swimming pools) and under-predict up to 6 thousand $\mathrm{m}^{3}$ as compared to calibrated SCS-CN model. In the other hand, the AFM model tends to over-predicted up to 69 thousand $\mathrm{m}^{3}$ runoff (equivalent to 28 Olympic size swimming pools) and under-predict nearly 62 thousand $\mathrm{m}^{3}$ (equivalent to 25 Olympic size swimming pools). 


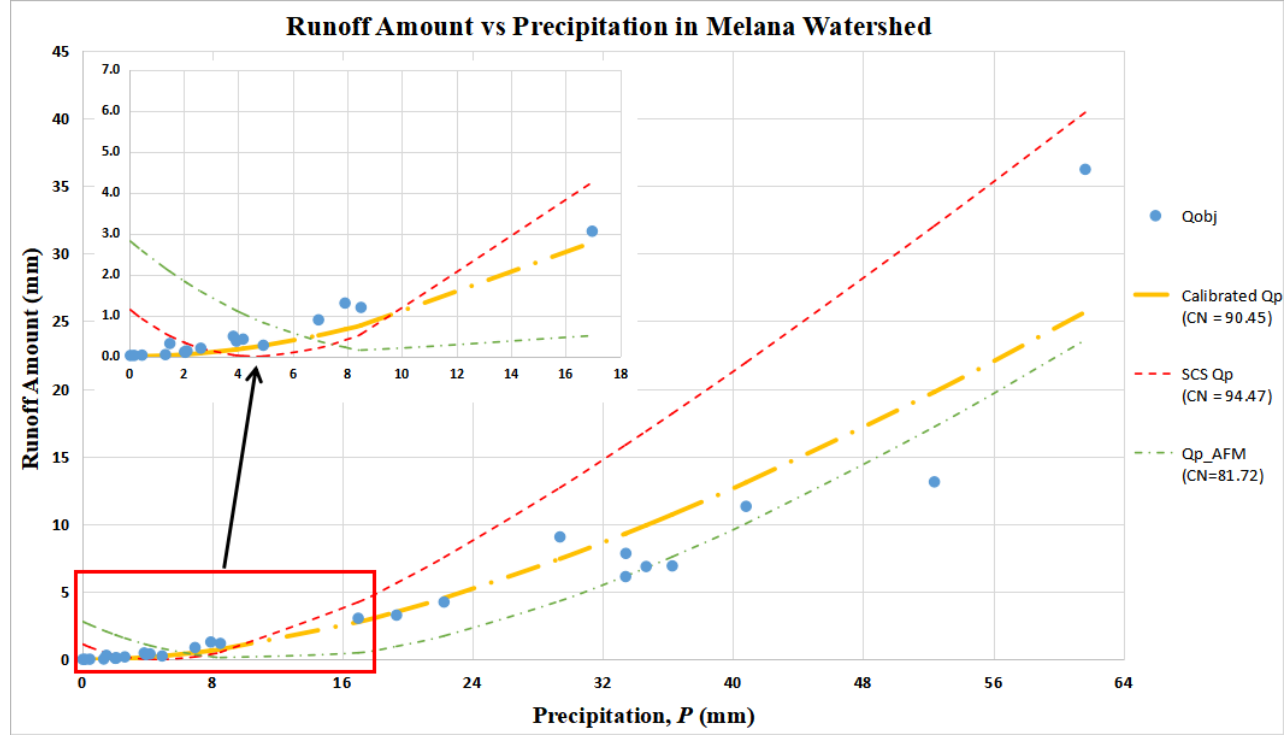

Fig. 9. Graph of Runoff Amount vs Precipitation in Melana Watershed

\section{Conclusion}

Conclusion, the $C N$ should not select from the NRCS handbook. By using the new $C N$ derivation approach with supervised numerical optimization technique under the guide of non-parametric inferential statistics can overcome the difficulty of selecting an accurate $C N$ from tabulated handbook. Throughout this study, the regional specific calibrated runoff predicted model performs better than SCS-CN model and asymptotic curve number fitting method. The derived $C N$ of Melana watershed is 90.45 under statistical significant at alpha 0.01 level. The predicted runoff results from conventional SCS-CN model tend to 326 thousand $\mathrm{m}^{3}$ which is equivalent to 130 Olympic size swimming pools and under-predict up to 6 thousand $\mathrm{m}^{3}$. Lastly, the new two decimal point $C N$ system should be applied instead of rounding up the $C N$. Although the $C N$ value derived from asymptotic $C N$ method is two decimal point of $C N$ value, the new $C N$ derivation approach still performs better with the proof of higher $R$ value, lower $B I A S$ and lesser $R S S$ are obtained. The $C N$ value determined by asymptotic $C N$ method for Melana site is 81.72 which has tendency over-predicted up to 69 thousand $\mathrm{m}^{3}$ runoff (equivalent to 28 Olympic size swimming pools) and under-predict nearly 62 thousand $\mathrm{m}^{3}$ (equivalent to 25 Olympic size swimming pools).

\section{References}

1. E.A. Baltas, N.A. Dervos, M.A. Mimikou, HESS, 11, 1825-1829 (2007)

2. K. Banasik, D. Woodward, Empirical Determination of Runoff Curve Number for a Small Agricultural Watershed in Poland, $2^{\text {nd }}$ Joint Federal Interagency Conference, Las Vegas, NV, 10 (2010)

3. K. Banasik, Predicting the Flood Hydrographs for Small Urban Watersheds (in Polish), Warsaw University of Life Sciences - SGGW Press, Warsaw (2009)

4. F. Canters, J. Chormanski, T. Van de Voorde, O. Batelaan, Effects of Different Methods for Estimating Impervious Surface cover on Runoff Estimation at Catchment 
Level. In Proceedings of 7th International Symposium on Spatial Accuracy Assessment in Natural Resources and Environmental Sciences, Lisbon, Portugal, 557-566 (2006)

5. C.H. Chan, Modelling Watershed Cumulative Effects On Runoff Based On Major Land Uses, MS Thesis (2005)

6. R.G. Cronshey, R.T. Roberts, N. Miller, Urban Hydrology for Small Watersheds (TR55 Rev.), Hydraulics and Hydrology in the Small Computer Age: Proceedings of the Specialty Conference,(1985)

7. D.R. Cox, Principles of Statistical Inference (2006)

8. F. D’Asaro, G. Grillone, R.H. Hawkins, J.Hydrol.Eng, 17, 1141-1152 (2012)

9. F. D'Asaro, G. Grillone, R.H. Hawkins, J. Hydrol. Eng., 19, 04014035-1-13 (2014)

10. A.C. Davison, D.V. Hinkley, Bootstrap Methods and Their Application (1997)

11. B. Efron, R. Tibshirani, An Introduction to the Bootstrap (1994)

12. B. Efron, Large-Scale Inference: Empirical Bayes Methods for Estimation, Testing, and Prediction (2010)

13. M. Elhakeem, A. N. Papanicolaou, Water Resour Manag, 23, 2455-2473 (2009)

14. F. Fan, Y. Deng, X. Hu, Q. Weng, Remote Sens., 5, 1425-1438 (2013)

15. S. Gajbhiye, S.K. Mishra, Application of NRSC-SCS curve number model in runoff estimation using $R S$ and GIS. In: IEEE-ICAESM, 346-352 (2012)

16. R. H. Hawkins, A Comparison of Predicted and Observed Runoff Curve Numbers, Water today and tomorrow, Symp. Proc., ASCE, Reston, VA, 702-709 (1984)

17. R. H. Hawkins, J. Irrig. Drain. Eng., 119, 334-345 (1993)

18. R.H. Hawkins, A.V. Khojeini, Initial Abstraction and Loss in the Curve Number Method, Arizona State Hydrological Society Proceedings, 115-119 (2000)

19. R.H. Hawkins, T.J. Ward, D.E. Woodward, J.A. Van Mullem, Curve Number Hydrology: State of Practice, American Society of Civil Engineers, ASCE, 106 (2009)

20. R.H. Hawkins, Local Sources for Runoff Curve Numbers, In Proceedings of $11^{\text {th }}$ Annual Symposium of the Arizona Hydrological Society, 23-26 (1998)

21. R.H. Hawkins, T. J. Ward, Site and Cover Effects on Event Runoff, Jornada Experimental Range, New Mexico. In Proceddings: American Water Resource Association Conference on Rangeland Management and Water Resources, 361-370 (1998)

22. A.T. Hjelmfelt, Journal of Hydraulic Division, 106, 1471-1476 (1980)

23. R. Jiang, Investigation of Runoff Curve Number Initial Abstraction Ratio, MS Thesis (2001)

24. N.W. Kim, J.W. Lee, J.E. Lee, SWAT Application to Estimate Design Runoff Curve Number for South Korean Condition, Hydrol.Sci, 24, 2150-2170 (2010)

25. L. Ling, Z. Yusop, A micro focus with macro impact: Exploration of initial abstraction coefficient ratio ( $\lambda$ ) in Soil Conservation Curve Number (CN) methodology. IOP Conf. Ser: Earth Environ. Sci. 18 (2013).

26. L. Ling, Z. Yusop, Pertanika J.Sci.Technol. 25, 139-150 (2017)

27. L. Ling. Deriving The Initial Abstraction Ratio Coefficient for Runoff Prediction in Peninsula Malaysia. PhD Thesis (2017).

28. L. Ling, Z. Yusop, ARPN JEAS, 11, 9706-9711 (2016)

29. N.S. Magesh, N. Chandrasekar, J.P. Soundranayagam, Geosci. Front. 3(2), 189-196 (2012)

30. S.C. McCutcheon, Rainfall-runoff relationships for selected eastern U.S. forested mountain watersheds: Testing of the curve number method for flood analysis, Technical Rep., West Virginia Division of Forestry, Charleston, WV (2006) 
31. D.N. Moriasi, J.G. Arnold, M.W. Van Liew, R.L. Bingner, R.D. Harmel, T.L. Veith, 50, 885-900 (2007)

32. Majlis Perbandaran Johor Bahru Tengah (MPJBT), Rancangan Tempatan Skudai (1993-2010). Johor Bahru, Malaysia: Pihak Berkuasa Perancangan Tempatan Daerah Jahor Bahru (2001)

33. V.M. Ponce, R.H. Hawkins, J. Hydrol. Eng., 1, 11-19 (1996)

34. A. Rutkowska, S. Kohnova, K. Banasik, J. Szolgay, B. Karabova, JMS, 12, 533-548 (2015)

35. J. Roy, S. Saha, Int. Res. J. Earth Sci., 5, 1-7 (2017)

36. R.K. Sahu, S.K. Mishra, T.I. Eldho, J. Hydraul. Eng., 18, 27-36 (2012)

37. L.E. Schneider, R.H. McCuen, J.Irrig. Drain. Eng., 131, 282-290 (2005)

38. A.N. Sharpley, J.R. Williams, EPIC-Erosion/Productivity Impact Calculator: 1. Model Determination. U.S. Department of Agriculture Technical Bulletin, No. 1768, 235 (1990)

39. Z.H. Shi, L.D. Chen, N.F. Fang, D.F. Qin, C.F. Cai, Catena, 77, 1-7 (2009)

40. D. Stewart, E. Canfield, R. Hawkins, J. Hydraul. Eng., 17, 1180-1187 (2012)

41. C.A. Spruill, S.R. Workman, J.L. Taraba, Trans of American Society of Agricultural Engineers, 43, 1431-1439 (2000)

42. Soil Conservation Service (SCS), National Engineering Handbook, Sec. 4 Hydrology. (1964)

43. Soil Conservation Service (SCS), National Engineering Handbook, Sec. 4 Hydrology. (1972)

44. Soil Conservation Service (SCS), National Engineering Handbook, Sec. 4 Hydrology. (1985)

45. Soil Conservation Service (SCS), National Engineering Handbook, Sec. 4 Hydrology. (2001)

46. K.X. Soulis, J.D. Valiantzas, Water Resour, Manage, 27, 1737-1749 (2013)

47. K.X. Soulis, J.D. Valiantzas, N. Dercas, P.A., HESS, 13, 605-615 (2009)

48. N.H. Tedela, S.C. McCutcheon, J.L. Campbell, W.T. Swank, M.B. Adams, T.C. Rasmussen, J. Hydrol. Eng., 7, 1199-1203 (2011)

49. N.H. Tedela, S.C. McCutcheon, T.C. Rasmussen, R.H. Hawkins, W.T. Swank, J.L. Campbell, M.B. Adams, J. Hydrol. Eng., 17, 1188-1198 (2012)

50. D.E. Woodward, R.H. Hawkins, R. Jiang, A.T. Hjelmfelt, J.A. Van Mullem, Q.D. Quan, Runoff Curve Number Method: Examination of the Initial Abstraction Ratio, World Water \& Environmental Resources Congress, 1-10 (2003)

51. United States Department of Agriculture - Natural Resource Conservation Service (USDA-NRCS), Urban Hydrology for Small Watersheds TR-55 (1986)

52. G.A. Young, R.L. Smith, Essentials of Statistical Inference (2005)

53. Y. Yuan, W. Nie, S.C. McCutcheon, E.V. Taguas, Hydrol Process, 28, 774-783 (2014)

54. S.M. Yusuf, D. Guluda, T. Jayanegara, Surface Runoff Estimation from Various Land Use in Mapili Watershed using SCS Curve Number and Geographic Information System, IOP Conf. Series: Earth and Environmental Science 54 (2017)

55. X. Zhan, M.L. Huang, Environ. Modell. Softw. 19, 875-879 (2004)

56. S.M. Zhou, T.W. Lei, ASC, 44, 4240-4247 (2011) 